\title{
Tomographic filtering of geodynamic models: Implications for model interpretation and large-scale mantle structure
}

\author{
Jeroen Ritsema, ${ }^{1}$ Allen K. McNamara, ${ }^{2}$ and Abigail L. Bull ${ }^{2}$ \\ Received 14 June 2006; revised 10 August 2006; accepted 2 October 2006; published 27 January 2007.
}

[1] The resolution operator $\mathcal{R}$ is a critical accompaniment to tomographic models of the mantle. $\mathcal{R}$ facilitates the comparison between conceptual three-dimensional velocity models and tomographic models because it can filter these theoretical models to the spatial resolution of the tomographic model. We compute $\mathcal{R}$ for the tomographic model S20RTS (Ritsema et al., 1999, 2004) and two companion models that are based on the same data but derived with different norm damping values. The three models explain (within measurement uncertainty) S-SKS and S-SKKS travel times equally well. To demonstrate how artifacts distort tomographic images and complicate model interpretation, we apply $\mathcal{R}$ to (1) a thermochemical and (2) an isochemical model of convection in the mantle that feature different patterns of shear velocity heterogeneity in the deep mantle if we assume that shear velocity heterogeneity is caused by temperature variations only. $\mathcal{R}$ suppresses short-wavelength structures, removes strong velocity gradients, and introduces artificial stretching and tilting of velocity anomalies. Temperature anomalies in the thermochemical model resemble the spatial extent of low seismic velocity anomalies and the shear velocity spectrum in the D" region better than the isochemical model. However, the thermochemical model overpredicts the amplitude of shear velocity variation and places the African and Pacific anomalies imperfectly. We suspect that inaccurate velocity scaling laws and uncertain initial conditions control these mismatches. Extensive hypothesis testing is required to identify successful models.

Citation: Ritsema, J., A. K. McNamara, and A. L. Bull (2007), Tomographic filtering of geodynamic models: Implications for model interpretation and large-scale mantle structure, J. Geophys. Res., 112, B01303, doi:10.1029/2006JB004566.

\section{Introduction}

[2] Seismic tomography and mantle geodynamics are complementary research approaches. Since the pioneering work of Hager and O'Connell [1979, 1981], tomographic images have been key observational constraints to theoretical models of mantle convection. Geodynamical global flow models typically produce downwelling sheets of cold material which are associated with the positive wave speed anomalies seen in global tomographic models [e.g., Grand, 1994; Grand et al., 1997; Fukao et al., 2001]. Although the understanding of instantaneous, present-day global flow patterns relies on tomographic images to define a preexisting density structure [e.g., Hager et al., 1985; Hager and Richards, 1989; Becker and O'Connell, 2001], timedependent geodynamical models have failed to selfconsistently generate the broad (and presumable hot) regions in the lower mantle beneath Africa and Pacific comparable to

\footnotetext{
${ }^{1}$ Department of Geological Sciences, University of Michigan, Ann Arbor, Michigan, USA.

${ }^{2}$ Department of Geological Sciences, Arizona State University, Tempe, Arizona, USA.

Copyright 2007 by the American Geophysical Union. 0148-0227/07/2006JB004566\$09.00
}

those observed seismically [e.g., Dziewonski et al., 1977; Tanimoto, 1990; Su et al., 1994; Li and Romanowicz, 1996; Masters et al., 1996; Ritsema et al., 1999; Gu et al., 2001]. Whether these seismic structures are (poorly imaged) thermal upwellings in an effectively isochemical mantle [e.g., Bunge and Richards, 1996; Bunge et al., 1998; Lithgow-Bertelloni and Richards, 1998; Becker and Boschi, 2002; Schubert et al., 2004] or whether they are signatures of intrinsically dense piles or superplumes in the deep mantle [e.g., Thompson and Tackley, 1998; Davaille, 1999; Kellogg et al., 1999; Tackley, 2000; Forte and Mitrovica, 2001; Jellinek and Manga, 2002; Tackley, 2002; Davaille et al., 2003; Jellinek and Manga, 2004; Nakagawa and Tackley, 2004; Tan and Gurnis, 2005] remain outstanding questions.

[3] The significant differences in resolution complicate comparisons of geodynamical and seismic models. Geodynamical models are typically calculated on uniform meshes with a dense grid spacing on the order of $20 \mathrm{~km}$. The parameterization of tomographic models is at least an order of magnitude larger in scale and the tomographic model resolution is inherently spatially heterogeneous due to the incomplete and uneven seismic sampling of the mantle (Figure 1). In fact, tomographic model resolution can be counterintuitive and it cannot be fully characterized 


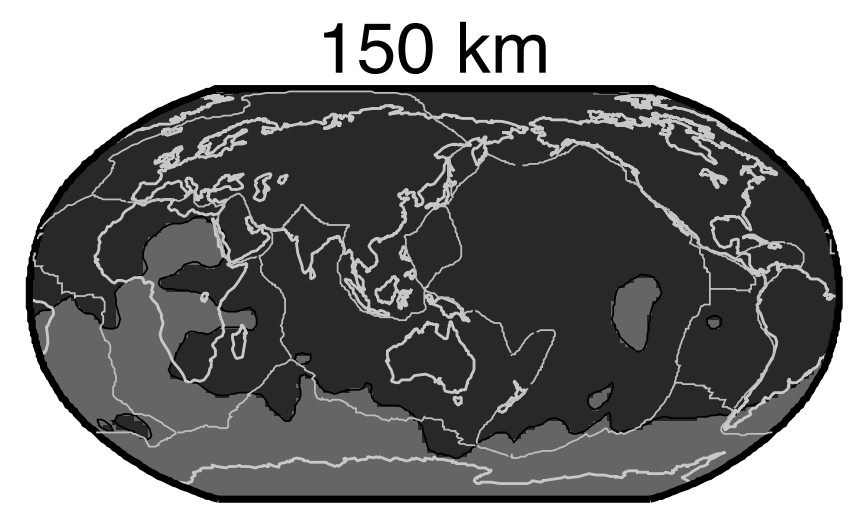

with few, generic resolution (e.g., "checkerboard" or "spike") tests [e.g., Lévêque et al., 1993].

[4] To ensure a meaningful interpretation, it is critical to properly filter the geodynamic model so that it features structural heterogeneity with the same spatial resolution. Mégnin et al. [1997] and Bunge and Davies [2001] mimic the effects of such a filter by inverting synthetic seismic observables computed for a geodynamic input model with the same procedures applied to real data. This approach is somewhat cumbersome because it requires that the synthetic data (e.g., waveforms and travel time picks), the forward modeling approach (e.g., waveform synthesis) and the inversion procedures (e.g., data weighing, earthquake relocation, parameterization, and regularization) are reproduced precisely. It would be valuable to nonexperts if tomographic models are accompanied by their resolution operator. This would enable them to compare any hypothetical model of mantle heterogeneity to seismic images without an understanding of the intricate details of seismic data selection and tomographic inversion procedures.

[5] Leaving a more complete comparison to a forthcoming publication, we illustrate here the effects of the tomographic resolution operator on thermochemical and isochemical end-member models of the deep mantle. These models have recently been discussed by McNamara and Zhong [2005]. While these authors suggest that direct comparisons of S20RTS [Ritsema et al., 1999, 2004] images to temperature fields indicate that the thermochemical mantle model yields the best match, we reevaluate these comparisons after the geodynamical models have been tomographically filtered. We begin with a summary of the determination of the seismic resolution operator following classic least-squares inversion methodology. Subsequently, we discuss the seismic resolution of velocity heterogeneity in the deep mantle and illustrate how the geodynamic models of the deep mantle are seen through tomographic eyes.

\section{Seismic Resolution Operator}

[6] In tomography, we typically relate seismic data $\mathbf{d}$ to a model $\mathbf{m}$ of wave speed variation in Earth in a linear fashion

$$
\mathbf{G m}=\mathbf{d},
$$

Figure 1. Estimates of vertical resolution of shear velocity heterogeneity in S20RTS at $150 \mathrm{~km}, 650 \mathrm{~km}, 1600 \mathrm{~km}$, and $2500 \mathrm{~km}$ depth from the vertical extent of Backus-Gilbert resolution kernels $\mathbf{K}\left(\mathbf{r}, \mathbf{r}_{0}\right)$. The resolution kernel is defined by $m^{\dagger}\left(\mathbf{r}_{0}\right)=\int_{V} d V \mathbf{K}\left(\mathbf{r}, \mathbf{r}_{0}\right) m^{t}(\mathbf{r})$ and describes how the value obtained in the generalized model $m^{\dagger}\left(\mathbf{r}_{0}\right)$ at $\mathbf{r}_{0}$ is a spatial average over the true structure $m^{t}(\mathbf{r})$. Vertical resolution is defined by the area under the vertical cross section through $\mathbf{K}$ that occupies $50 \%$ of the resolution kernel [see Ritsema et al., 2004]. While lateral variations in resolution are due to the uneven distribution of seismic stations and earthquakes, the variation in depth can be attributed to the variable resolving power of the various data types. 
Table 1. S-SKS and S-SKKS Travel Time Residuals and Model Fits

\begin{tabular}{lcccccc}
\hline & & & \multicolumn{3}{c}{ Average Residual Delay, s } \\
\cline { 5 - 7 } Model & $\epsilon$ & $\mathbf{N}$ & $\delta V_{S}$ in D”, \% & S-SKS Avg. Delay = 3.64 s & S-SKKS Avg. Delay $=5.49 \mathrm{~s}$ & MisFit Red., \% \\
\hline 1 & 0.075 & 2083 & -1.2 to +1.2 & 2.65 & 3.46 & 49 \\
2 (s20rts) & 0.035 & 2932 & -1.6 to +1.5 & 2.52 & 3.10 & 55 \\
3 & 0.015 & 4000 & -2.1 to +1.9 & 2.42 & 2.84 & 59 \\
\hline
\end{tabular}

and estimate $\mathbf{m}$ by damped least-squares inversion [e.g., Tarantola, 1987; Menke, 1989; Scales et al., 2001; Aster et al., 2005] to minimize

$$
\Gamma(\mathbf{m})=(\mathbf{G m}-\mathbf{d})^{T}(\mathbf{G m}-\mathbf{d})+\epsilon \mathbf{m}^{T} \mathbf{m} .
$$

The solution to (1) is

$$
\mathbf{m}^{\dagger}=\mathbf{G}^{\dagger} \mathbf{d}
$$

where $\mathbf{G}^{\dagger}$ is the generalized inverse of $\mathbf{G}$. If $\mathbf{U} \Lambda \mathbf{U}^{T}$ is the eigenvalue decomposition of $\mathbf{G}^{T} \mathbf{G}$, we can define the generalized inverse by

$$
\mathbf{G}^{\dagger}=\mathbf{U} \Lambda^{-1} \mathbf{U}^{T} \mathbf{G}^{T}
$$

where $\Lambda^{-1}=(\Lambda+\epsilon I)^{-1}$. Combining (1) and (3) yields

$$
\mathbf{m}^{\dagger}=\mathcal{R} \mathbf{m}^{\mathrm{t}}
$$

where we have defined the resolution operator $\mathcal{R}=\mathbf{G}^{\dagger} \mathbf{G}$ that specifies how the true Earth $\mathbf{m}^{\mathrm{t}}$ is mapped into the tomographic model $\mathbf{m}^{\dagger}$. The spatially heterogeneous resolution, an attribute of any tomographic model, is fully described by $\mathcal{R}$.

[7] By design, damping (via $\epsilon$ ) suppresses the magnitude of shear velocity variation in $\mathbf{m}^{\dagger}$ at the expense of data fit. Choosing an appropriate value for $\epsilon$ requires knowledge of data errors. Instead of $\epsilon$, we can express the amount of damping by $N$, the trace of the resolution operator $\mathcal{R}$. For model S20RTS we chose $\epsilon=0.035$ on the basis of the combined travel time and phase velocity fit. This damping is equivalent to choosing $N=2932$, meaning that 2932 effective unknowns have been resolved. It is straightforward to derive a tomographic model and its resolution $\mathcal{R}$ for any $\epsilon$. Ideally, the inspection of tomographic models and the application of the tomographic filter to geodynamic models is carried out for the full range of values for $\epsilon$ that yield acceptable data fits. Using (4), this is a relatively straightforward task.

[8] Table 1 summarized the results for three models derived using damping values $\epsilon=0.075$ (Model 1), $\epsilon=$ 0.035 (Model 2), and $\epsilon=0.015$ (Model 3). Model 2 is identical to S20RTS. The number of effective unknowns $(N)$ increases from 2083 to 4000 as $\epsilon$ decreases. The extreme damping factors are chosen based on the fit to $8700 \mathrm{~S}-\mathrm{SKS}$ and $1900 \mathrm{~S}-\mathrm{SKKS}$ differential travel times. These travel times are primarily affected by shear velocity heterogeneity in D" [e.g., Kuo et al. 2000]. All models explain the travel time data equally well. The average S-SKS delay of $3.64 \mathrm{~s}$ and S-SKKS delay of $5.49 \mathrm{~s}$ are reduced after inversion to values that range from 2.65 to $2.42 \mathrm{~s}$ and 3.46 to $2.84 \mathrm{~s}$, respectively. These ranges are small compared to the estimated $0.5 \mathrm{~s}$ measurement errors.

[9] Figure 2 shows the shear velocity heterogeneity in D" for Model 1, Model 2, and Model 3. Since Model 1 is damped the most and Model 3 is damped the least, the shear velocity variations in $\mathrm{D}$ " are smallest $(-1.2$ to $+1.2 \%)$ in Model 1 and highest $(-2.1$ to $+1.9 \%)$ in Model 3. In addition, shear velocity variations are smoothest in Model 1 due to relatively strong damping. The uncertain amplitude of velocity heterogeneity is a consequence of measurement uncertainty and scatter. It is inherent to any tomographic models given the integral constraints by travel times [see also Montelli et al., 2004].

\section{Application to End-Member Convection Models}

[10] We illustrate the effects of the tomographic filter for a thermochemical, $\mathrm{TC}_{\mathrm{IN}}$, and an isochemical, $\mathrm{IC}_{\mathrm{IN}}$, model of the deep mantle [McNamara and Zhong, 2005]. The filtered versions are $\mathrm{TC}_{\mathrm{OUT}}$ and $\mathrm{IC}_{\mathrm{OUT}}$, respectively. The convection models are developed using the thermochemical extension [McNamara and Zhong, 2004] of CitcomS [Zhong et al., 2000] and employ Earth-like convection vigor, temperature, and depth-dependent rheology and surface plate motions for the past 120 million years [Lithgow-Bertelloni and Richards, 1998]. Model $\mathrm{TC}_{\mathrm{IN}}$ includes a relatively dense layer in the lowest $225 \mathrm{~km}$ of the mantle that has been perturbed by convective motions. Its intrinsic density contrast is denoted by the buoyancy ratio [McNamara and Zhong, 2004]. Apart from the addition of this basal layer $\mathrm{TC}_{\mathrm{IN}}$ employs model parameters identical to $\mathrm{IC}_{\mathrm{IN}}$.

[11] We assume that shear velocity variations are only caused by temperature variations in the mantle. We scale the temperature from the geodynamical models to wave speed by first determining the average temperature at each depth. We define the wave speed anomaly to be 0 at that temperature. Lateral shear velocity variations are determined by scaling departures from the average temperature to shear velocity perturbations using $d V_{S} / d T=-7.0 \times 10^{-5} \mathrm{~km} \mathrm{~s}^{-1}$ $\mathrm{K}^{-1}$ following Forte and Mitrovica [2001].

[12] The geodynamical models predict fundamentally different shear velocity patterns. The intrinsically dense basal layer in the thermochemical model is focused into a large ridge-like structure beneath Africa and a superposition of ridges beneath the Pacific [McNamara and Zhong, 2005]. These dense piles are significantly hotter than the ambient mantle and produce broad thermal anomalies with a similar shape and location as the low shear velocity anomalies seen tomographically. The isochemical model comprises a net- 


\section{A S-SKS and S-SKKS traveltimes}

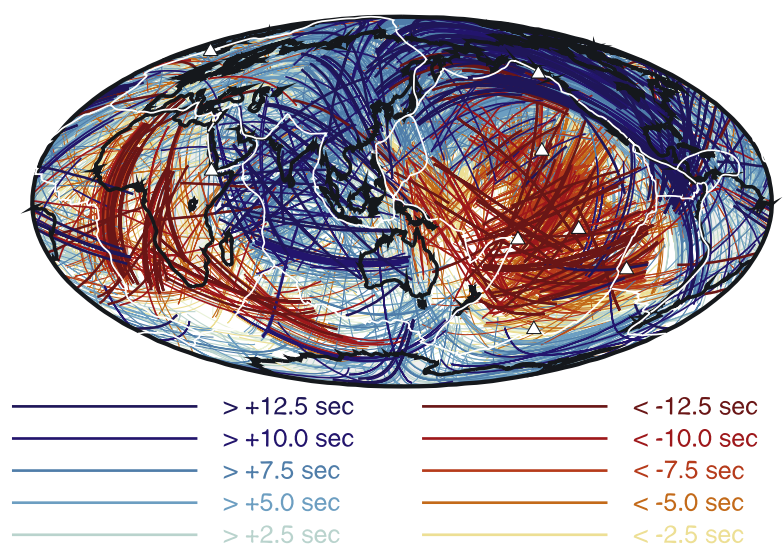

\section{B Shear velocity variation in D"}
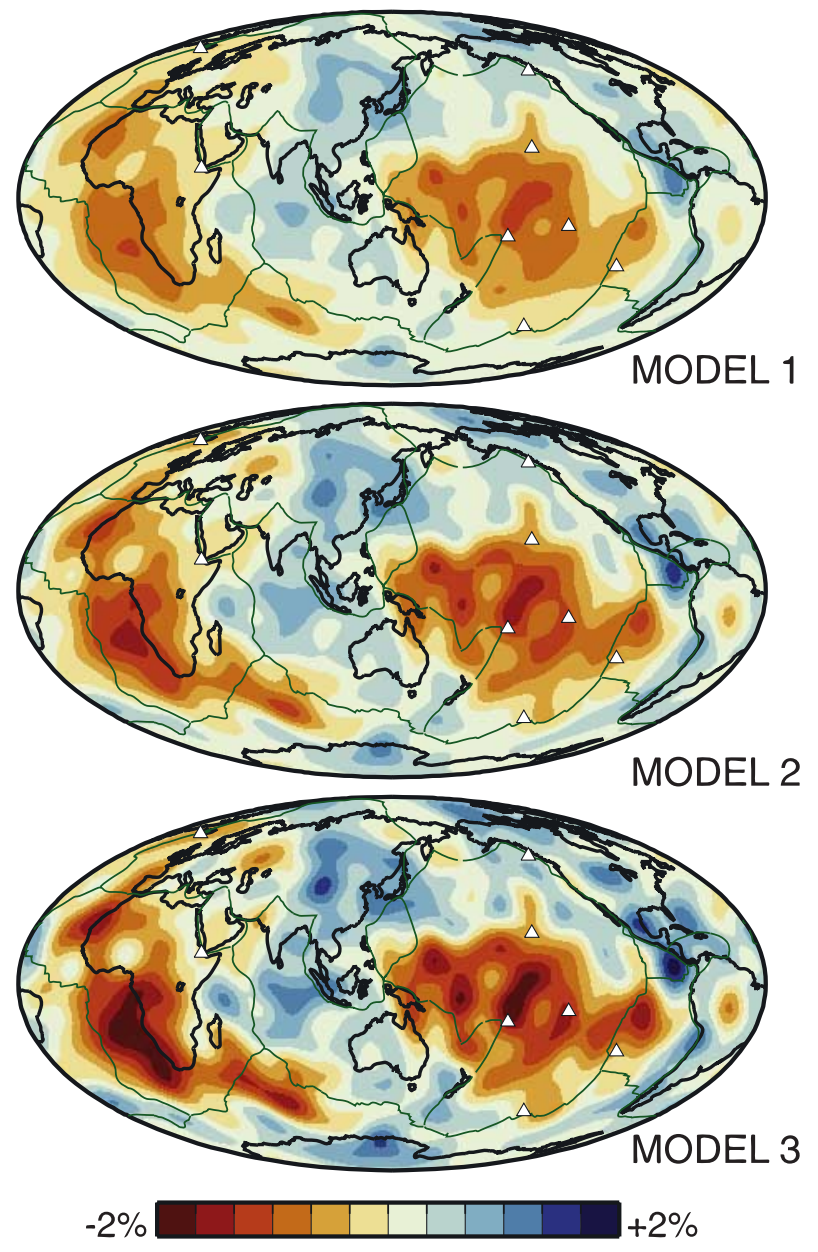

Figure 2. (a) Surface projected segments of $\mathrm{S}$ and diffracted S wave ray paths through the bottom $200 \mathrm{~km}$ of the mantle. The segments are colored red (blue) if the corresponding S-SKS or S-SKKS differential travel time is higher (lower) than the PREM value. The coherent geographic distribution of the travel time anomalies is well reflected by the shear velocity variation in D", shown in Figure 2b. (b) Shear velocity variations at $2750 \mathrm{~km}$ depth in Model 1, Model 2, and Model 3 derived using different norm damping parameters $\epsilon$ (see Table 1). work of thin, linear upwellings that are clustered beneath Africa and the Pacific.

\subsection{D" Heterogeneity Maps}

[13] D" maps (Figure 3) illustrate how $\mathcal{R}$ filters the geodynamic input models $\left(\mathrm{TC}_{\mathrm{IN}}\right.$ and $\left.\mathrm{IC}_{\mathrm{IN}}\right)$ into models ( $\mathrm{TC}_{\text {OUT }}$ and $\mathrm{IC}_{\text {OUT }}$ ) with the resolution of S20RTS. Lowpass filtering is a first-order effect of $\mathcal{R}$. The strong variations $(20 \%)$ of shear velocity in $\mathrm{TC}_{\mathrm{IN}}$, strong gradients along the edges low velocity anomalies, and the narrow, linear anomalies of $\mathrm{IC}_{\mathrm{IN}}$ in $\mathrm{D}$ " are smoothed and suppressed especially in regions (e.g., Africa) with sparse data coverage. However, the models retain their contrasts after tomographic filtering. For example, the linear low velocity anomalies in $\mathrm{IC}_{\mathrm{IN}}$ are smoother in $\mathrm{IC}_{\mathrm{OUT}}$ but they are not projected into a single low velocity anomaly.

[14] $\mathcal{R}$ accentuates the degree-2 D" heterogeneity in $\mathrm{TC}_{\mathrm{OUT}}$ and $\mathrm{IC}_{\mathrm{OUT}}$ that characterizes the seismic models. Figure 4 shows the spectrum of shear velocity in the D" region as a function of model damping. Model $\mathrm{TC}_{\text {OUT }}$ matches the strong reduction of spectral amplitude seen in the spectrum of Model 2 better than $\mathrm{IC}_{\text {OUT. }}$. However, the shear speed variations in $\mathrm{TC}_{\mathrm{OUT}}$ are at least a factor of two larger than in Model 2 and the ring structure of the "African anomaly" in $\mathrm{TC}_{\mathrm{OUT}}$ is not seen in Model 2.

\subsection{Whole-Mantle Cross Sections}

[15] Vertical cross sections through the mantle (Figure 5) demonstrate several artifacts that $\mathcal{R}$ introduces in the images. For example, the central Pacific low-velocity anomalies in $\mathrm{IC}_{\mathrm{OUT}}$ and $\mathrm{TC}_{\mathrm{OUT}}$ extend higher than in $\mathrm{IC}_{\mathrm{IN}}$ and $\mathrm{TC}_{\mathrm{IN}}$, respectively, and they are artificially tilted toward the northeast due to the predominant northeasterly ray coverage in the Pacific mantle. However, the easterly tilt of the African anomaly in S20RTS [Ritsema et al., 1999] cannot be dismissed as an artifact since tilting is not seen in the images of $\mathrm{TC}_{\text {OUT }}$. Smaller-scale instabilities that erupt from the edges of the thermochemical piles [e.g., Davaille, 1999; Jellinek and Manga, 2002; Davaille et al., 2005] in $\mathrm{TC}_{\mathrm{IN}}$ cannot be resolved tomographically (i.e., $\mathrm{TC}_{\mathrm{OUT}}$ ) at the resolution of S20RTS. High-velocity anomalies in D" that feature prominently in $\mathrm{TC}_{\mathrm{IN}}$ to the east and west of the African anomaly are missing or have significantly reduced amplitude in $\mathrm{TC}_{\mathrm{OUT}}$ due to the lack of seismic sampling in this region [e.g., Wysession, 1996].

[16] The model comparison indicates several characteristics of $\mathrm{TC}_{\mathrm{IN}}$ and $\mathrm{IC}_{\mathrm{IN}}$ that are inconsistent with Model 2 even after $\mathcal{R}$ has been applied. The convection models predicts a relatively strong high-velocity anomaly in the lower mantle beneath North America (the signature of Farallon subduction [e.g., Grand, 1994; Tan et al., 2002]), that dips in a direction opposite from what is observed tomographically.

\section{Discussion and Conclusions}

[17] It is critical that the interpretation of tomographic models incorporates comprehensive studies of model resolution. The resolution of tomographic models is spatially heterogeneous. The resolution operator $\mathcal{R}$ can be computed in a straightforward manner when $\mathbf{G}^{T} \mathbf{G}$ is determined by, for example, singular value decomposition (equation (4)). 

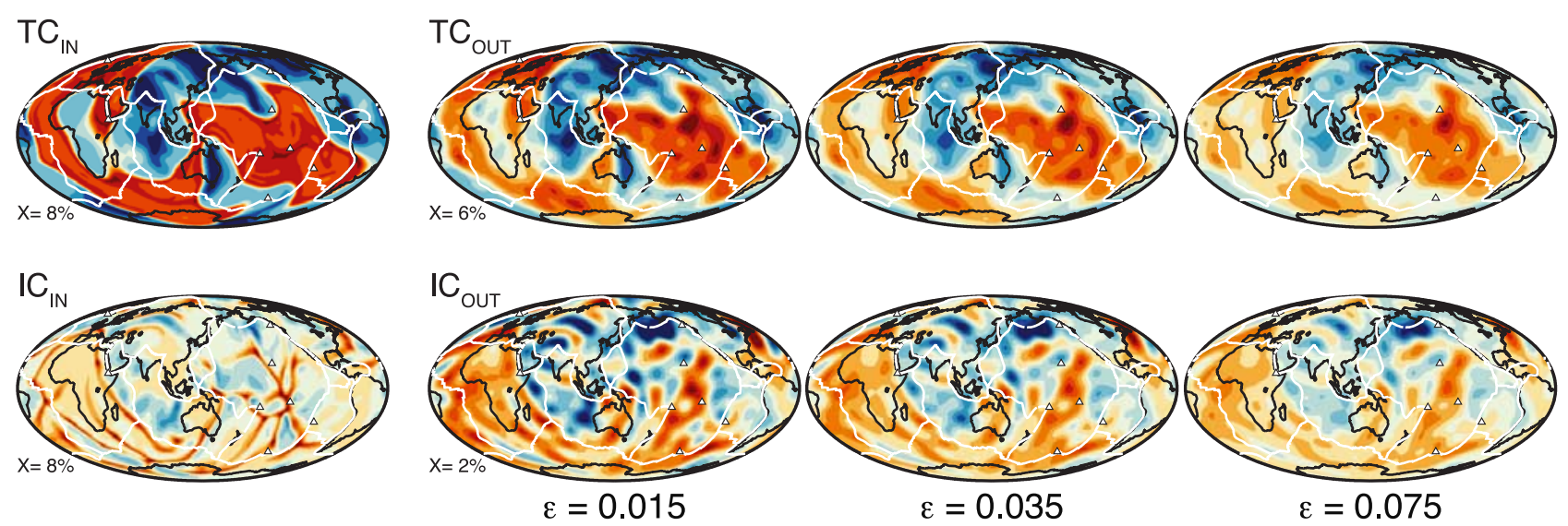

Figure 3. Shear velocity variations at $2750 \mathrm{~km}$ depth in (upper left) $\mathrm{TC}_{\mathrm{IN}}$ and (lower left) $\mathrm{IC}_{\mathrm{IN}}$ and, to their right, the tomographically filtered models $\mathrm{TC}_{\mathrm{OUT}}$ and $\mathrm{IC}_{\mathrm{OUT}}$ determined for $\mathcal{R}$ that correspond to values for the damping parameter $\epsilon$ of $0.015,0.035$, and 0.075 . The color scale is the same as in Figure 2 . The shear velocity varies from $-\mathrm{X} \%$ to $+\mathrm{X} \%$ in order to display the shear velocity variations across the full color spectrum. $\mathrm{X}=8 \%$ for $\mathrm{TC}_{\mathrm{IN}}$ and $\mathrm{IC}_{\mathrm{IN}}, \mathrm{X}=6 \%$ for $\mathrm{TC}_{\mathrm{OUT}}$, and $\mathrm{X}=2 \%$ for $\mathrm{IC}_{\mathrm{OUT}}$. Triangles are hotspots from the compilation of Ritsema and Allen [2003].

Application of $\mathcal{R}$ to conceptual models of shear velocity in the mantle allows for a more meaningful comparison to tomographic models because it filters them to the same resolution and introduces modeling artifacts that distort the tomographic images.

[18] Applications to a thermochemical $\left(\mathrm{TC}_{\mathrm{IN}}\right)$ and isochemical $\left(\mathrm{IC}_{\mathrm{IN}}\right)$ model of convection illustrates that low-pass filtering is a first-order effect of $\mathcal{R}$. Amplitudes of especially short-wavelength shear velocity variations are reduced and sharp velocity gradients are suppressed. However, the key differences between $\mathrm{TC}_{\mathrm{IN}}$ and $\mathrm{IC}_{\mathrm{IN}}$ are retained in $\mathrm{TC}_{\mathrm{OUT}}$ and $\mathrm{IC}_{\text {OUT. }}$. The $\mathrm{D}^{\text {" spectrum of }} \mathrm{TC}_{\mathrm{OUT}}$ is dominated by the lower harmonic degrees while $\mathrm{IC}_{\mathrm{OUT}}$ features elongated (albeit smoother) linear low-velocity structure in D" that reflect narrow upwellings. These characteristics are robust over a range of damping values for which comparable misfit reductions of S-SKS and S-SKKS travel times are obtained. Tomographic model resolution is therefore sufficiently high to assess the applicability of models $\mathrm{TC}_{\mathrm{IN}}$ and $\mathrm{IC}_{\mathrm{IN}}$.

[19] $\mathrm{TC}_{\text {OUT }}$ is the preferred model as it provides a better match to the shape of the seismic spectrum of D" heterogeneity than $\mathrm{IC}_{\mathrm{OUT}}$. In addition, the shear velocity structure in Model 2 correlates best with the structure in $\mathrm{TC}_{\mathrm{OUT}}$ throughout the lower mantle (Figure 6). These results corroborate other seismological observations that point to thermochemical heterogeneity in the deep mantle [e.g., Su and Dziewonski, 1997; Kennett et al., 1998; Ritsema et al., 1998; Ishii and Tromp, 1999, 2004; Masters et al., 2000; Forte and Mitrovica, 2001; Wen et al., 2001; Ni et al., 2002; Deschamps and Trampert, 2003; Trampert et al., 2004; Wang and Wen, 2004].
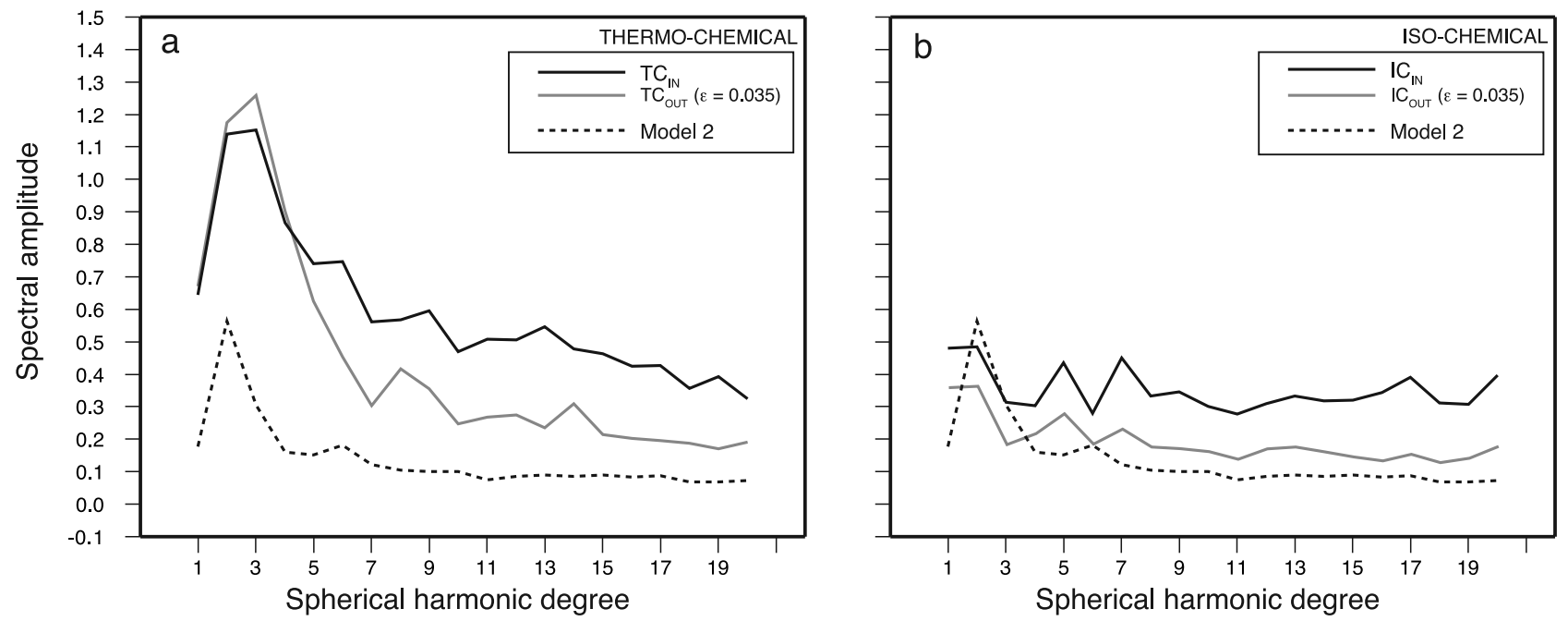

Figure 4. Spectral amplitude as a function of spherical harmonic degree of shear velocity heterogeneity in D" for Model 2 (S20RTS), (a) $\mathrm{TC}_{\mathrm{IN}}$ and $\mathrm{TC}_{\mathrm{OUT}}$, and (b) $\mathrm{IC}_{\mathrm{IN}}$ and $\mathrm{IC}_{\text {OUT }}$. $\mathrm{TC}_{\mathrm{OUT}}$ and $\mathrm{IC}_{\mathrm{OUT}}$ are determined for $\epsilon=0.035$. 
Thermo-chemical
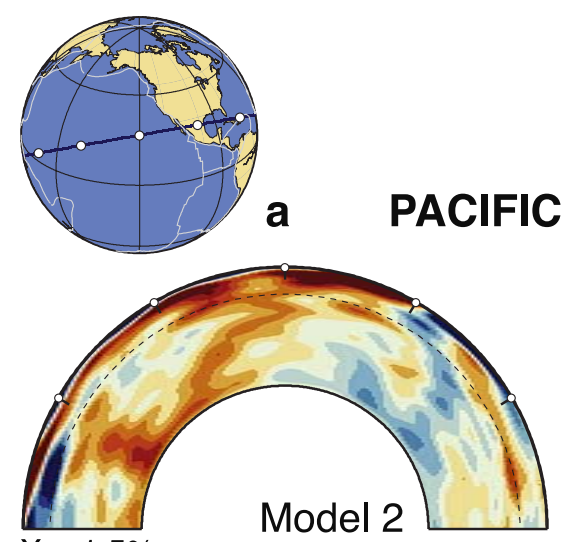

$\mathrm{X}=1.5 \%$ a PACIFIC
Model 2
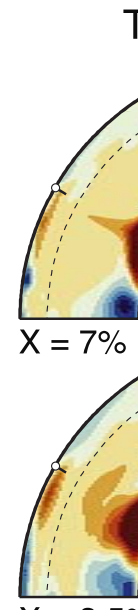

$X=3.5 \%$
$\mathrm{TC}_{\mathrm{O}}$

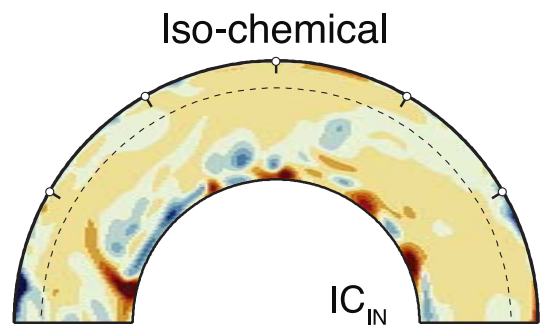

$\mathrm{TC}_{\text {IN }}$

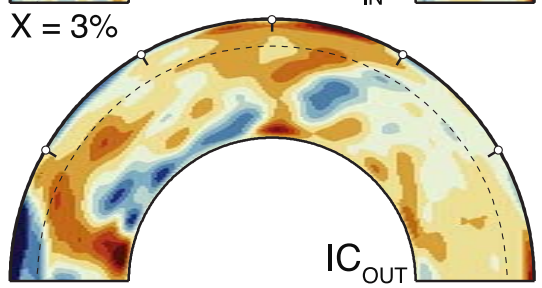

$X=1.0 \%$

$\mathrm{IC}_{\mathrm{ou}}$
-X shear velocity perturbation from 1-D +X

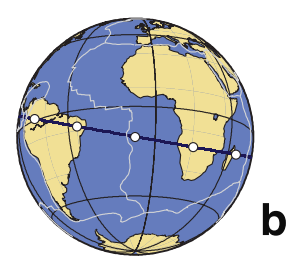

b ATLANTIC

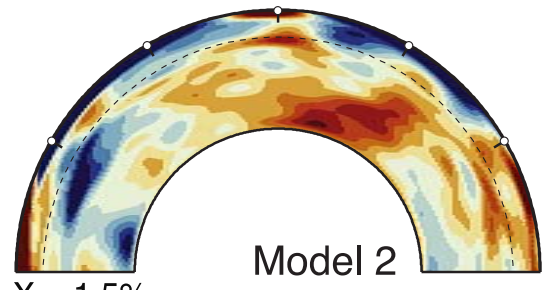

$X=1.5 \%$

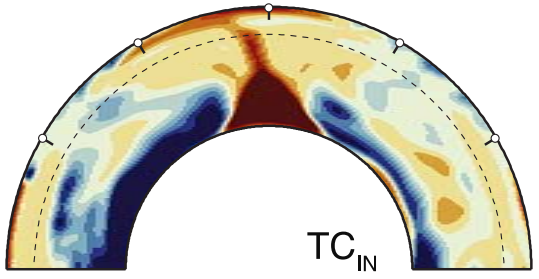

$X=7 \%$

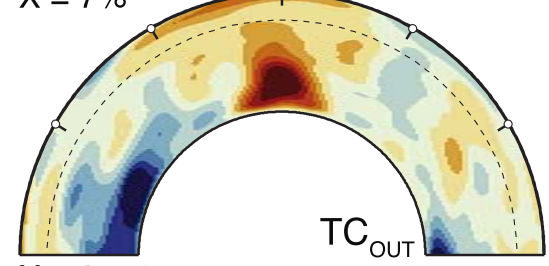

$X=3.5 \%$

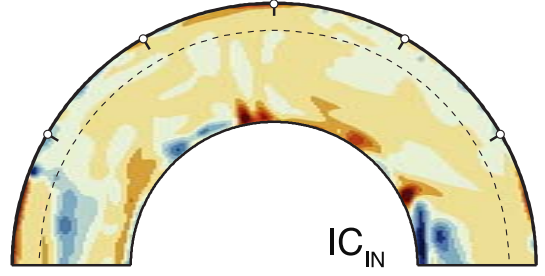

$X=3 \%$

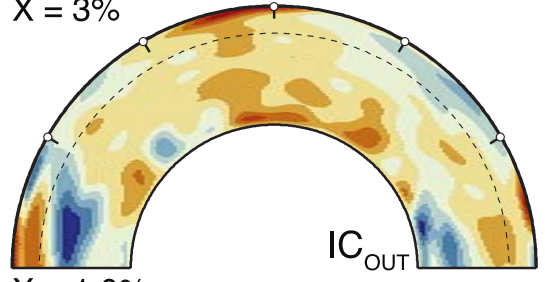

$X=1.0 \%$

Figure 5. Shear velocity heterogeneity in whole-mantle cross-sections through (a) the Pacific and North America, and (b) the Atlantic and southern Africa according to (left) Model 2 (S20RTS), (middle) $\mathrm{TC}_{\mathrm{IN}}$ and $\mathrm{TC}_{\mathrm{OUT}}$, and (right) $\mathrm{IC}_{\mathrm{IN}}$ and $\mathrm{IC}_{\mathrm{OUT}}$ (filtered using $\epsilon=0.035$ ). The color scale is the same as in Figure 2. The shear velocity varies from $-\mathrm{X} \%$ to $+\mathrm{X} \%$ in order to display the shear velocity variations across the full color spectrum. $\mathrm{X}$ is given below each cross section.

[20] However, we readily acknowledge that there is considerable mismatch between the tomographic models and $\mathrm{TC}_{\mathrm{OUT}}$. This is obvious in the shear velocity images of Figures 2 and 5 and it is reflected by low correlation values for spherical harmonic degrees larger than 6 . This indicates either tomographic model artifacts that are not represented by $\mathcal{R}$ (i.e., errors in the forward problem) or inaccuracies in the geodynamic models. For example, the purely temperature dependent wave speed conversion may not be justified and may underly the large mismatch in the amplitude of shear velocity variations in $\mathrm{TC}_{\text {OUT }}$ and the tomographic models. Moreover, prescribed initial conditions, especially uncertainties in the plate velocities in the geologic past, may have a major effects on the location of anomalies in the mantle. In ongoing research, we are investigating the role of composition and depth-dependent temperature to wave speed conversions [e.g., Stixrude and Lithgow-Bertelloni, 2005] and we examining the effects of uncertain initial conditions.

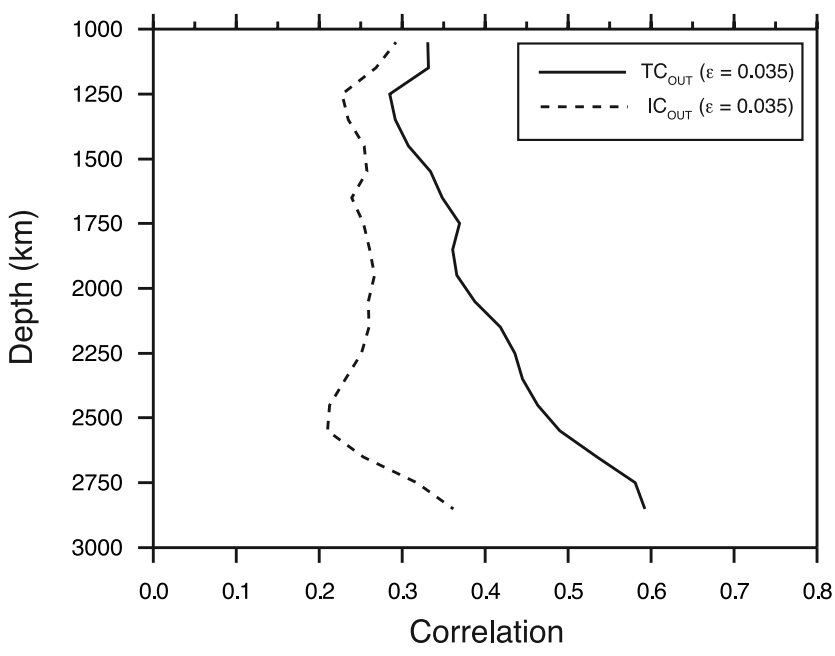

Figure 6. Cross-correlation coefficient between Model 2 (S20RTS), (sold line) $\mathrm{TC}_{\mathrm{OUT}}$, and (dashed line) $\mathrm{IC}_{\mathrm{OUT}}$ for a damping value $\epsilon=0.035$. 
[21] It is key not to draw general conclusions concerning the applicability of thermochemical and isochemical model aspects on the basis of two resolution tests. We believe that we have demonstrated that seismic tomography can be used to discriminate between isochemical and thermochemical structures but the generality has to be explored with a large number of cases. To this end, we make $\mathcal{R}$ available to interested research groups for further quantitative comparison of dynamic models and S20RTS.

[22] Acknowledgments. All figures were generated with the GMT software of Wessel and Smith [1995]. The IRIS and GEOSCOPE Data Centers provided seismological data. We thank Matt Fouch for valuable discussions and Jeannot Trampert, Jun Korenaga, and Michael Ritzwoller for constructive reviews. This research has been funded by NSF grants EAR-0609763 (JR) and EAR-0510383 (AKM).

\section{References}

Aster, R. C., B. Borchers, and C. H. Thurber (2005), Parameter Estimation and Inverse Problems, Elsevier, New York.

Becker, T. W., and L. Boschi (2002), A comparison of tomographic and geodynamic mantle models, Geochem. Geophys. Geosys., 3(1), 1003 , doi:10.1029/2001GC000168.

Becker, T. W., and R. J. O'Connell (2001), Predicting plate velocities with mantle circulation models, Geochem. Geophys. Geosys., 2(2), doi:10.1029/2001GC000171.

Bunge, H. P., and J. H. Davies (2001), Tomographic images of a mantle circulation model, Geophys. Res. Lett., 28, 77-80.

Bunge, H. P., and M. A. Richards (1996), The origin of large scale structure in mantle convection: effects of plate motions and viscosity stratification, Geophys. Res. Lett., 23, 2987-2990.

Bunge, H. P., M. A. Richards, C. Lithgow-Bertelloni, J. R. Baumgardner, S. P. Grand, and B. Romanowicz (1998), Time scales and heterogeneous structure in geodynamic Earth models, Science, 280, 91-95.

Davaille, A. (1999), Simultaneous generation of hotspots and superswells by convection in a heterogeneous planetary mantle, Nature, 402, 756760 .

Davaille, A., M. L. Bars, and C. Carbonne (2003), Thermal convection in a heterogeneous mantle, C. R. Geosci., 335, 141-156.

Davaille, A., E. Stutzmann, G. Silveira, J. Besse, and V. Courtillot (2005), Convective patterns under the Indo-Atlantic box, Earth Planet. Sci. Lett., $239,233-252$.

Deschamps, F., and J. Trampert (2003), Mantle tomography and its relation to temperature and composition, Phys. Earth Planet. Int., 140, 277-291.

Dziewonski, A. M., B. H. Hager, and R. J. O'Connell (1977), Large scale heterogeneity in the lower mantle, J. Geophys. Res., 82, 239-255.

Forte, A. M., and J. X. Mitrovica (2001), Deep-mantle high viscosity flow and thermochemical structure inferred from seismic and geodynamic data, Nature, 410, 1049-1056.

Fukao, Y., S. Widiyantoro, and M. Obayashi (2001), Stagnant slabs in the upper and lower mantle transition region, Rev. Geophys., 39, 291-323.

Grand, S. P. (1994), Shear mantle structure beneath the Americas and the surrounding oceans, J. Geophys. Res., 99, 11,591-11,621.

Grand, S. P., R. D. van der Hilst, and S. Widiyantoro (1997), Global seismic tomography: A snapshot of convection in the Earth, GSA Today, 7, 1-7.

Gu, Y. J., A. M. Dziewonski, and G. Ekström (2001), Preferential detection of the Lehmann discontinuity beneath continents, Geophys. Res. Lett., 28, $4655-4658$.

Hager, B. H., and R. J. O’Connell (1979), Kinematic models of large-scale flow in the Earth's mantle, J. Geophys. Res., 84, 1031-1048.

Hager, B. H., and R. J. O'Connell (1981), A simple global model of plate dynamics and mantle convection, J. Geophys. Res., 86, $4843-$ 4867.

Hager, B. H., and M. A. Richards (1989), Long-wavelength variations in Earth's geoid: Physical models and dynamical implications, Phil. Trans. R. Soc. London, Ser. A., 328, 209-327.

Hager, B. H., R. W. Clayton, M. A. Richards, R. P. Comer, and A. M. Dziewonski (1985), Lower mantle heterogeneity, dynamics topography and the geoid, Nature, 313, 541-545.

Ishii, M., and J. Tromp (1999), Normal-mode and free-air gravity constraints on lateral variations in velocity and density of Earth's mantle, Science, 285, 1231-1236.

Ishii, M., and J. Tromp (2004), Constraining large-scale mantle heterogeneity using mantle and inner-core sensitive normal modes, Phys. Earth Planet. Int., 146, 113-124.
Jellinek, A. M., and M. Manga (2002), The influence of a chemical boundary layer on the fixity, spacing, and lifetime of mantle plumes, Nature, 418 , $760-763$

Jellinek, A. M., and M. Manga (2004), Links between long-lived hot spots, mantle plumes, D", and plate tectonics, Rev. Geophys., 42, RG3002, doi:10.1029/2003RG000144.

Kellogg, L. H., B. H. Hager, and R. D. van der Hilst (1999), Compositional stratification in the deep mantle, Science, 283, 1881-1884.

Kennett, B. L. N., S. Widiyantoro, and R. D. van der Hilst (1998), Joint seismic tomography for bulk sound and shear wave speed in the Earth's mantle, J. Geophys. Res., 103, 12,469-12,493.

Kuo, B. Y., E. J. Garnero, and T. Lay (2000), Tomographic inversion on S-SKS times for shear velocity heterogeneity in D": Degree 12 and hybrid models, J. Geophys. Res., 105, 28,139-28,157.

Lévêque, J. J., L. Rivera, and G. Wittlinger (1993), On the use of the checkerboard test to assess the resolution of tomographic inversions, Geophys. J. Int., 115, 313-318.

Li, X. D., and B. Romanowicz (1996), Global mantle shear velocity model developed using nonlinear asymptotic coupling theory, J. Geophys. Res., $101,22,245-22,272$

Lithgow-Bertelloni, C., and M. A. Richards (1998), The dynamics of Cenozoic and Mesozoic plate motions, Rev. Geophys., 36, 27-78.

Masters, G., S. Johnson, G. Laske, and H. Bolton (1996), A shear velocity model of the mantle, Phil. Trans. R. Soc. London, Ser. A, 354, 13851411.

Masters, G., G. Laske, H. Bolton, and A. Dziewonski (2000), The relative behavior of shear velocity, bulk sound speed, and compressional velocity in the mantle: Implications for chemical and thermal structure, in Earth's Deep Interior: Mineral Physics and Tomography from the Atomic to the Global Scale, Geophys. Monogr. Ser., vol. 117, edited by S. Karato, et al., pp. 63-87, AGU, Washington, D. C.

McNamara, A. K., and S. Zhong (2004), Thermochemical structures within a spherical mantle: Superplumes or piles?, J. Geophys. Res., 109, B07402, doi:10.1029/2003JB002847.

McNamara, A. K., and S. Zhong (2005), Thermochemical structures beneath Africa and the Pacific, Nature, 437, 1136-1139.

Mégnin, C., H. P. Bunge, B. Romanowicz, and M. A. Richards (1997), Imaging 3-D spherical convection models: What can seismic tomography tell us about mantle dynamics?, Geophys. Res. Lett., 24, 1299-1302.

Menke, W. (1989), Geophysical Data Analysis: Discrete Inverse Theory, 289 pp., Elsevier, New York.

Montelli, R., G. Nolet, G. Masters, F. A. Dahlen, and S.-H. Hung (2004), Global P and PP traveltime tomography: Rays versus waves, Geophys. J. Int., $158,637-654$.

Nakagawa, T., and P. J. Tackley (2004), Effects of thermo-chemical mantle convection on the thermal evolution of the Earth's core, Earth Planet. Sci. Lett., 220, 107-119.

Ni, S., E. Tan, M. Gurnis, and D. V. Helmberger (2002), Sharp sides to the African superplume, Science, 296, 1850-1852.

Ritsema, J., and R. M. Allen (2003), The elusive mantle plume, Earth Planet. Sci. lett., 207, 1-12.

Ritsema, J., S. Ni, D. V. Helmberger, and H. P. Crotwell (1998), Anomalous shear velocity reductions and gradients in the lower mantle beneath Africa, Geophys. Res. Lett., 25, 4245-4248.

Ritsema, J., H. J. van Heijst, and J. H. Woodhouse (1999), Complex shear velocity structure imaged beneath Africa and Iceland, Science, 286, $1925-1928$

Ritsema, J., H. J. van Heijst, and J. H. Woodhouse (2004), Global transition zone tomography, J. Geophys. Res., 109, B02302, doi:10.1029/ 2003JB002610.

Scales, J. A., M. L. Smith, and S. Treitel (2001), Introductory Geophysical Inverse Theory, Samizdat, location?

Schubert, G., G. Masters, P. Olson, and P. Tackley (2004), Superplumes or plume clusters?, Phys. Earth Planet. Int., 146, 147-162.

Stixrude, L., and C. Lithgow-Bertelloni (2005), Mineralogy and elasticity of the oceanic upper mantle: Origin of the low-velocity zone, J. Geophys. Res., 110, B03204, doi:10.1029/2004JB002965.

Su, W. J., and A. M. Dziewonski (1997), Simultaneous inversion for 3-d variations in shear and bulk velocity in the mantle, Phys. Earth Planet. Int., 100, 135-156.

Su, W. J., R. L. Woodward, and A. M. Dziewonski (1994), Degree-12 model of shear velocity heterogeneity in the mantle, J. Geophys. Res., 99, 6945-6980

Tackley, P. (2000), Mantle convection and plate tectonics: Toward an integrated physical and chemical theory, Science, 288, 2002-2007.

Tackley, P. (2002), Strong heterogeneity caused by deep mantle layering, Geochem. Geophys. Geosys., 3(4), doi:10.1029/2001GC000167.

Tan, E., and M. Gurnis (2005), Metastable superplumes and mantle compressibility, Geophys. Res. Lett., 32, L20307, doi:10.1029/ 2005GL024190. 
Tan, E., M. Gurnis, and L. Han (2002), Slabs in the lower mantle and their modulation of plume formation, Geochem. Geophys. Geosys., 3(11), 1067, doi:10.1029/2001GC000238.

Tanimoto, T. (1990), Long-wavelength S-wave velocity structure throughout the mantle, Geophys. J. Int., 100, 327-336.

Tarantola, A. (1987), Inverse Problem Theory, Elsevier, New York.

Thompson, P. F., and P. J. Tackley (1998), Generation of megaplumes from the core-mantle boundary in a compressible mantle with temperature-dependent viscosity, Geophys. Res. Lett., 25, 1999-2002.

Trampert, J., F. Deschamps, J. Resovsky, and D. Yuen (2004), Probabilistic tomography maps chemical heterogeneities throughout the lower mantle, Science, 306, 853-856.

Wang, Y., and L. Wen (2004), Mapping the geometry and geographic distribution of a very low velocity province at the base of the Earth's mantle, J. Geophys. Res., 109, B10305, doi:10.1029/ 2003JB002674.
Wen, L., P. G. Silver, D. James, and R. Kuehnel (2001), Seismic evidence for a thermo-chemical boundary layer at the base of the Earth's mantle, Earth Planet. Sci. Lett., 189, 141-153.

Wessel, P., and W. H. F. Smith (1995), New version of the generic mapping tools released, Eos Trans. $A G U, 76,329$

Wysession, M. E. (1996), How well do we utilize global seismicity?, Bull. Seismol. Soc. Am., 86, 1207-1219.

Zhong, S., M. T. Zuber, L. Moresi, and M. Gurnis (2000), The role of temperature-dependent viscosity and surface plates in spherical shell models of mantle convection, J. Geophys. Res., 105, $11,063-11,082$.

A. L. Bull and A. K. McNamara, Department of Geological Sciences, Box 871404, Tempe, AZ 85287, USA.

J. Ritsema, Department of Geological Sciences, University of Michigan, 2534 C.C. Little, 1100 N. University, Ann Arbor, MI 48109, USA (jritsema@umich.edu) 